\title{
The verbal overshadowing effect: Why descriptions impair face recognition
}

\author{
CHAD S. DODSON and MARCIA K. JOHNSON \\ Princeton University, Princeton, New Jersey \\ and \\ JONATHAN W. SCHOOLER \\ University of Pittsburgh, Pittsburgh, Pennsylvania
}

\begin{abstract}
Three experiments explored the verbal overshadowing effect, that is, the phenomenon that describing a previously seen face impairs recognition of this face. There were three main results: First, a verbal overshadowing effect was obtained both when subjects were provided with and when they generated a description of an earlier seen face. Second, instructing subjects at the time of test to be aware of potentially competing memories did not improve, and may even have worsened, recognition performance when the subjects had generated a description of the target face. However, these instructions improved performance and eliminated the verbal overshadowing effect when subjects were provided with someone else's description of the target face. Third, recognition of the target face was disrupted when subjects described a completely different face, such as their parent's face or a face of the opposite sex. The results are discussed in relation to two potential mechanisms: source confusion between previously encoded visual and verbal representations of the face and a shift in processing of the test faces at recognition.
\end{abstract}

How well we remember an event depends in part on the criteria we use to evaluate the information that comes to mind (e.g., Dodson \& Johnson, 1993; Hasher \& Griffin, 1978; Jacoby, Kelley, Brown, \& Jasechko, 1989; Lindsay \& Johnson, 1989; Raye, Johnson, \& Taylor, 1980). The way we are oriented to examine our memory can affect the kind and amount of memorial information that we use to make a memory judgment. For instance, in the misleadingsuggestion paradigm (e.g., Lindsay \& Johnson, 1989; Loftus, Miller, \& Burns, 1978; McCloskey \& Zaragoza, 1985 ), subjects may view a slide sequence and then receive an ostensibly accurate written description of the seen material. But, the description contains misleading information, introducing new items or referring to peripheral items that were seen in the slides as something else. On a final recognition test for the seen information, subjects often respond on the basis of the misleading information, claiming to have seen items that were only read about. In essence, subjects confuse the sources of the information, mistakenly reporting that the misinformation was ac-

This research was funded in part by a National Science Foundation graduate fellowship to the first author, Grants AG09253 and AG09744 from the National Institute on Aging to the second author, and a grant from the National Institute on Mental Health to the third author. For their helpful comments, we would like to thank Barb Chalfonte and other members of the Princeton Memory Lab: Jennifer Bonilla, Allison Hermann, Scott Nolde, John Reeder, Sarah Smith, and Christine Voegeli. We would also like to thank Steve Lindsay, Geoff Loftus, and Mike McCloskey for their helpful comments. Correspondence should be directed to C. S. Dodson, Department of Psychology, University of California, Berkeley, CA 94720 (e-mail: chadd@violet.berkeley.edu). quired during the slide sequence (Johnson, Hashtroudi, \& Lindsay, 1993).

Although the misinformation effect is robust when standard recognition tests are used, other studies have found fewer source confusions when subjects were given a source-monitoring test that oriented them to assess their memory in terms of the possible sources of the learned information (Lindsay \& Johnson, 1989; Zaragoza \& Koshmider, 1989; Zaragoza \& Lane, 1994). That is, for each item on the test, subjects needed to indicate whether it had been seen, read, both seen and read, or was new. Lindsay and Johnson (1989) suggested that criterial differences between the recognition and source-monitoring tests might explain the differences found in the probability of making source confusions. Most recognition tests query subjects only about whether the target item was in the slide sequence, and the questions may be answered according to the item's degree of familiarity; the most familiar items are marked as having been seen in the slides. In contrast, most source tests orient subjects to use different, perhaps stricter, criteria and to evaluate memory in terms of all the possible sources for the target item (e.g., was it read, seen, both read and seen, or new?). Accurate judgments of this sort cannot be based only on familiarity, but must rely on more specific memorial information (e.g., how much and what type of perceptual detail and cognitive operations did it include?) (see, e.g., Johnson et al., 1993). Another technique that seems to direct subjects away from relying solely on familiarity is to warn them before they receive the standard recognition test that the postevent narrative was inaccurate (e.g., Christiaansen \& Ochalek, 1983). In this case, the misinformation effect diminishes, 
presumably because the warning induces subjects to distinguish between their memory for what was read in the narrative and their memory for what was seen in the slides.

Other paradigms have also demonstrated that subjects sometimes fail to distinguish between memories of visual and verbal information under certain encoding and test conditions (e.g., Durso \& Johnson, 1980; Intraub \& Hoffman, 1992). For instance, in a study by Intraub and Hoffman, subjects initially viewed a sequence of unrelated slides showing various ordinary scenes, such as a boy and his father at the zoo. The subjects then read a series of paragraphs describing some of the scenes they had seen in the slides and some scenes that were new to them. On a final test, the subjects were presented with the previously experienced items and the novel items and were asked to identify the source of each item. Intraub and Hoffman found that subjects often confused descriptions of scenes that they had only read about with scenes that they had previously seen as pictures; they often claimed to have seen in picture form items that they had actually only read about. Evidently, when subjects read the paragraph they incidentally imaged the scene that was depicted, and then mistakenly interpreted their memory of this imaginal information as indicating that the item had actually been seen. However, Dodson and Johnson (1993) showed that fewer source confusions occurred in this paradigm when subjects were given a source-monitoring test that explicitly oriented them to examine their memory for an item in terms of all the possible sources.

Schooler and his colleagues (Fallshore \& Schooler, 1995; Schooler \& Engstler-Schooler, 1990; Schooler, Ryan, \& Reder, 1996) have reported a phenomenon that, on the face of it, appears similar to the false recognitions obtained in the paradigms used by Loftus et al. (1978) and Intraub and Hoffman (1992). Schooler and EngstlerSchooler (1990) initially showed subjects a video of a bank robbery, and subsequently directed half of the subjects to describe the robber and the other half (the control subjects) to complete a filler activity. Schooler and Engstler-Schooler found that subjects were worse at recognizing the previously seen robber from a line-up of similar looking faces when the subjects had described his face than when they had not done so. Schooler and EngstlerSchooler argued that the control subjects, who had not described the face, based their recognition decisions on their visual memory of the face, whereas the verbalization subjects were biased to rely on their memory of how they had described the face. Their verbal memory overshadowed their visual memory. Apparently, the subjects who described the face performed poorly when they relied on their verbally biased representation, because the face had been described in only a general way and provided a weak basis for discriminating between the similar looking faces at the test. However, Schooler and Engstler-Schooler found that the verbal overshadowing effect disappeared when subjects were forced to make a recognition decision within $5 \mathrm{sec}$ of seeing the test faces. The results from the speeded-response condition indi- cate that the visual representation is still available to and relied upon by the verbalization subjects under the proper test conditions.

These results suggest that even under nonspeeded conditions, the number of false recognitions might be reduced if subjects could be induced to examine their memories more carefully, as in the misleading-suggestion and visual/ verbal scene paradigms, assuming that similar processes account for the errors in these different paradigms (e.g., Dodson \& Johnson, 1993; Lindsay \& Johnson, 1989). That is, when subjects describe a previously seen face, they may imagine the face while they describe it, just as subjects may incidentally imagine misleading information or described scenes. During the recognition test, subjects may confuse their memory of how they imagined the face with their memory of seeing the face, and rely on this memory of the imagined face (a type of failure in reality monitoring; Johnson \& Raye, 1981). Presumably errors occur because the memory of the imagined face is less accurate than the visual memory and thus provides less guidance during the test for choosing the target face. If so, the verbalization subjects might be more accurate, that is, fewer source confusions should occur, when they are oriented during the recognition test to be aware of these separate memory representations and are encouraged to rely on their more accurate visual representation of the face.

Experiment 1 was designed to examine this sourceconfusion explanation of the verbal overshadowing effect. We used a video showing the target face and a corresponding test slide that had been used by Schooler and Engstler-Schooler (1990, Studies 1, 2, 4, and 5) to demonstrate the verbal overshadowing effect. We included the verbal/self-paced-test and the control/self-paced-test conditions in order to replicate the impairment effect. We also included verbal/speeded-test and control/speeded-test conditions in which subjects had a limited amount of time to make a recognition decision. Schooler and EngstlerSchooler (1990, Study 6) found improved performance in the verbal/speeded-test condition when an acquisition face was initially presented as a static slide. Of interest to us was whether the advantage of speeded responding would also occur when a face had been studied under more natural, dynamic viewing conditions, such as during a video presentation. The few studies that have systematically compared memory for faces presented via slides or videos have found no effect on subsequent recognition performance (Bruce, 1994; Bruce \& Valentine, 1988). Therefore, we expected to replicate Schooler and EngstlerSchooler's finding in the speeded-test condition.

In addition, there were two manipulations that were intended to make subjects who had described the face aware of their separate visual and verbal memory representations of the target face. In the verbal/ignore condition, subjects were told that these two memory representations might differ in how accurately they captured the face and that they should ignore their memories of what they wrote and base their recognition decisions on what they saw. Christiaansen and Ochalek (1983) used a variation of this 
ignore manipulation in a study involving the misleadingsuggestion paradigm, and found that subjects were more accurate when they received instructions to ignore information presented after the initial target event than when they did not. In another group (verbal/two-choice), we told subjects that we were interested in learning how aware people were of differences between their visual memories of a face and their memories of their verbal descriptions of the face. Accordingly, we asked subjects to choose two faces during the recognition test: one that matched their visual memories and one that matched their verbal descriptions. As a control group for this last condition, we asked another group of subjects, who had not described the face, to choose two faces: one that matched their memories of the robber's face and one that was the best alternative. On the basis of prior findings from other paradigms (Dodson \& Johnson, 1993; Lindsay \& Johnson, 1989; Zaragoza \& Lane, 1994), we expected that both verbal/ignore and verbal/two-choice would encourage subjects to assess the properties of their memories carefully and thereby reduce the verbal overshadowing effect.

\section{EXPERIMENT 1}

\section{Method}

Subjects. The subjects were 140 male and female volunteers who were Princeton students; each was paid for his/her participation. The subjects were assigned randomly to conditions, with 20 subjects in each.

Procedure. All subjects viewed a 30-sec videotape depicting a robber entering a bank, walking toward the camera, and demanding "Just follow the instructions; don't press the alarm and you won't get hurt." This was the same videotape segment that was used by Schooler and Engstler-Schooler (1990). All subjects then participated in a 20-min filler activity that consisted of completing reading comprehension problems from the Graduate Record Examination (Educational Testing Service, 1989). Afterwards, all subjects were assigned randomly to one of seven conditions. In four of these conditions (verbalization conditions), the subjects were encouraged to spend 5 min writing a description of the previously seen robber. They were told to "try to use the full five minutes, describing in as much detail as possible the facial features of this robber." In the remaining three conditions (control conditions), the subjects spent 5 min completing more reading comprehension problems. Finally, all subjects were shown a slide containing eight similar looking faces, including the face of the previously seen robber. They also received a sheet of paper with instructions appropriate for this condition. There were eight boxes on the sheet that corresponded to the eight faces on the slide. Each subject was asked to put a "V" in the box that represented the face that they had seen in the video. A more detailed explanation of each condition follows.

In the control/self-paced and the verbal/self-paced conditions, subjects were asked to choose the face that corresponded to their memory of the face of the robber. They were told to put a "V" in the box that matched their memory of it.

In the control/speeded-test and verbal/speeded-test conditions, the subjects were told before seeing the test slide that they would "have only five seconds to review the faces and to indicate if one of the faces matches" their memory of the face of the robber. It was emphasized that they would see the slide for only $5 \mathrm{sec}$ and that they should decide immediately after viewing the slide. They were instructed to put a "V" in the box that corresponded to their memory of the robber.
Before viewing the test slide, subjects in the verbal/ignore condition were instructed:

We're interested in how aware people are of the differences between their memory for seeing a face and their memory for having described a face. It is rare that these two memories are identical, especially since people's descriptions rarely match (in all ways) what they described. When people see the original face again, these differences between their initial memory for the face and their memory for their description sometimes become apparent. In completing the following task, you should ignore your memory for how you described the face and only rely on your memory for seeing the face.

These subjects then saw the slide and were asked to put a "V" in the box that corresponded to their memory of the face of the robber.

Before viewing the slide, the subjects in the verbal/two-choice condition were told:

We're interested in how aware people are of the differences between their memory for seeing a face and their memory for having described this face. It is rare that these two memories are identical, especially since people's descriptions rarely match (in all ways) what they described. When people see the original face again, these differences between their initial memory for the face and their memory for their description become apparent.

These subjects were then asked to put a "V" in the box that matched their memory of the face they had seen in the video and to put a " $D$ " in the box that matched their written descriptions. Subjects in the control/two-choice condition were told to put a " $\mathrm{V}$ " in the box that corresponded to their memory of the face of the robber and to put a "V2" in the box that represented the best alternative face that corresponded to their memory of the robber. In both of these two-choice conditions, recognition performance was computed from only the "V" responses.

All subjects were given the option of saying that the face was not present. After choosing the box or boxes, depending on the test instructions, all subjects were then asked to indicate their confidence in their choices on a scale from 1 (guessing) to 9 (certain). In the two-choice conditions, the subjects were directed to assess their confidence in their " $V$ " choices.

\section{Results}

Unless otherwise noted, the results were significant at $p<.05$

Table 1 presents both the mean percentage correct recognition and combined recognition and confidence scores for all conditions. This combination score, which has a range of 1 to 6 , reflects the confidence and accuracy of subjects and penalizes subjects who express confidence in inaccurate choices. The combined score was

Table 1

Recognition and Recognition Weighted by Confidence Scores for Experiment 1

\begin{tabular}{cccc}
\hline & $\begin{array}{c}\text { Percentage } \\
\text { Correct } \\
\text { Recognition }\end{array}$ & $\begin{array}{c}\text { Recognition } \\
\times \text { Confidence } \\
\text { Scores }\end{array}$ & $S E$ \\
\hline $\begin{array}{c}\text { Self-paced test } \\
\text { Control }\end{array}$ & 80 & 4.95 & .39 \\
$\quad$ Verbal & 65 & 4.20 & .51 \\
$\begin{array}{c}\text { Speeded test } \\
\quad \text { Control }\end{array}$ & 70 & 4.30 & .38 \\
$\quad$ Verbal & 35 & 3.20 & .37 \\
Two-choice & & 4.25 & .51 \\
$\quad$ Control & 65 & 3.85 & .49 \\
$\quad$ Verbal & 55 & 3.30 & .45 \\
Ignore & & & \\
$\quad$ Verbal & 45 & & \\
\hline
\end{tabular}


computed in the following manner: When subjects made an incorrect choice and indicated the following level of confidence, score $=1$ (confidence is $7,8,9)$, score $=2$ (confidence is $4,5,6$ ), and score $=3$ (confidence is 1,2 , 3 ); when subjects made a correct choice, score $=4$ (confidence is $1,2,3)$, score $=5$ (confidence is $4,5,6$ ), score $=6($ confidence is $7,8,9)$. Although the combination score and the proportion correct recognition show the same general pattern, as seen in Table 1, group differences were more apparent, statistically, with the combination score, and therefore that measure was used in the following analyses.

The first analysis examined two questions: First, does describing a previously seen face impair subsequent recognition of this face (the verbal overshadowing effect)? And second, does the verbal overshadowing effect disappear under speeded-response conditions relative to nonspeeded conditions? That is, with a static slide, Schooler and Engstler-Schooler (1990) found the verbal overshadowing effect in the self-paced conditions (.80 in the control condition and .50 in the verbalize condition), and they found no difference in recognition performance between these two conditions when the test was completed under speeded conditions (.76 in the control condition and .73 in the verbalize condition). A $2 \times 2$ analysis of variance (ANOVA) was conducted on the first four conditions in Table 1 and yielded main effects of control versus verbal $\left[F(1,76)=4.97, M S_{\mathrm{e}}=3.44\right]$ and self-paced versus speeded test $[F(1,76)=3.96, p<.051]$ and no interaction. Subjects who had described the face were less accurate than subjects who had not described the face, and subjects were less accurate when they had to make speeded recognition decisions than when their decisions were self-paced. Although we replicated the verbal overshadowing effect in the self-paced conditions, we found no evidence that the verbal overshadowing effect was reduced under speeded as compared with self-paced test conditions. As seen in Table 1, our failure to replicate was not due to floor or ceiling effects (Loftus, 1978). If anything, we found a larger verbal overshadowing effect in the speeded than in the self-paced conditions.

The second analysis tested our prediction that encouraging subjects to examine their memories more carefully would reduce the verbal overshadowing effect. Contrary to our expectations, subjects in the verbal/ignore condition performed significantly less accurately than subjects in the control/self-paced condition $[F(1,133)=6.83$, $\left.M S_{\mathrm{e}}=3.99\right]$ and worse, but not significantly so, than subjects in the verbal/self-paced condition $[F(1,133)=2.03]$. Similarly, subjects in the verbal/two-choice condition were less accurate than subjects in the control/self-paced condition $[F(1,133)=3.04, p<.10]$, although they were not significantly worse than subjects in the control/twochoice condition $[F(1,133)=.40]$.

\section{Discussion}

There were three main results to this study: (1) We replicated the verbal overshadowing effect - that is, the finding that subjects are worse at recognizing a target face when they had earlier described the face than when they had not described the face; (2) we did not replicate Schooler and Engstler-Schooler's (1990) finding that the verbal overshadowing effect is reduced under speededtest conditions; and (3) contrary to our prediction, we did not reduce the verbal overshadowing effect when we directed subjects to be aware of their potentially competing visual and verbal representations of the target face (i.e., with the two-choice and ignore test conditions). In short, the verbal overshadowing effect persisted under speededresponse conditions and under conditions designed to make subjects consider more carefully the information that was presumably driving their recognition judgments.

Our failure to replicate Schooler and Engstler-Schooler's (1990) finding in the speeded-test conditions is not idiosyncratic to our experiment. Read and Schooler (1994) also found a verbal overshadowing effect under speededtest conditions when subjects saw a video at study. There are a number of reasons why subjects might have been affected differently by speeding up the test, depending on whether they had seen a slide (Schooler \& EngstlerSchooler, 1990) or a video (our Experiment 1; Read \& Schooler, 1994) at study. Static versus dynamic encoding might result in qualitatively different underlying memory representations. The memory representation for a static face might be less complex than the memory representation for a face derived from dynamic information. Accessing the simpler representation might be easier or more direct under speeded conditions than accessing the more complex representation. Alternatively, variations in the match between study and test conditions (i.e., study slide and test slide or study video and test slide) might influence the impact of specific retrieval manipulations, such as speeded responding. That is, according to the idea of encoding specificity or transfer-appropriate processing (Morris, Bransford, \& Franks, 1977; Tulving, 1983), accessing the visual representation should be easier and perhaps less susceptible to verbal interference when the study and test conditions are similar (i.e., Schooler \& Engstler-Schooler's use of a slide at study and test) than when the test conditions are different (i.e., Read \& Schooler's and our use of a video at study and a slide at test). While it is not possible to determine precisely why slide versus video may differentially interact with verbalization, we suspect that the mode of presentation is important in mediating verbal overshadowing effects.

Our failure to reduce the verbal overshadowing effect with the verbal/ignore and verbal/two-choice conditions was intriguing, because, in other similar paradigms, performance was better when subjects were oriented toward examining their memory in terms of possible sources than when subjects received tests that oriented them toward relying on overall familiarity (Dodson \& Johnson, 1993; Lindsay \& Johnson, 1989; Zaragoza \& Lane, 1994). In the misleading-suggestion paradigm, for instance, subjects who have received misleading postevent information perform worse than control subjects because they appear to confuse their memories of information from the slides and 
the narrative and incorrectly rely on the narrative information. There are fewer source confusions in the misleadingsuggestion paradigm when subjects are specifically directed to be aware of the slides and the narrative as possible sources for a memory.

Despite the similarities between the verbal overshadowing and the misleading-suggestion paradigms, specific confusion between previously encoded representations may not account for the errors in the verbal overshadowing paradigm. Instead, an alternative explanation of the verbal overshadowing effect is that writing a description of a previously seen face induces a change in the way subjects examine the test faces (Schooler, 1989). The act of verbalization may induce a featural orientation at the time of test that is independent of the quality of the subject's description of the face. This featural orientation may take the form of a process-of-elimination strategy in which particular faces are excluded on the basis of an examination of certain features, such as the shape of the nose or eyes. Subjects may rely on verbalizable features at the expense of not considering nonverbal information. The control subjects, on the other hand, may rely on a more holistic strategy during the test in which their memory of the target face is globally matched with the alternative test faces. There is evidence that recognition performance is worse with a featural than with a holistic strategy (e.g., Carey \& Diamond, 1977; Diamond \& Carey, 1986; Dunning \& Stern, 1994; Rhodes, Brake, Taylor, \& Tan, 1989; Stern \& Dunning, 1994). Carey and Diamond showed that face recognition can involve global and featural information, but that recognition performance is usually better when subjects rely on global rather than on featural information (Carey \& Diamond, 1977; Diamond \& Carey, 1986). Similarly, people's ability to recognize faces is worse after judging the physical features (e.g., how large is the nose) than after judging the traits (e.g., honest?) of a face (e.g., Baddeley, 1979; Bower \& Karlin, 1974; Wells \& Hryciw, 1984; Wells \& Turtle, 1987; Winograd, 1976). Presumably, judging traits induces holistic processing of test faces.

Research suggests that featural processing of test faces may be closely linked to earlier verbalization of the target face. For example, Wells and Turtle (1987) found that although trait encoding leads to superior face recognition, featural encoding leads to superior verbal descriptions, as determined by independent raters. If verbalization is associated with featural processing, and if featural processing leads to poorer recognition performance, then it seems reasonable that verbalization might impair performance by encouraging a featural strategy at the time of test. Consistent with this view, Fallshore and Schooler (1995) found that the detrimental effects of verbalization were lessened by two factors known to promote featural processing at recognition: other race recognition (cf. Rhodes, Brake, Taylor, \& Tan, 1989) and inversion (Diamond \& Carey, 1986).

If the effect of verbalization is not simply to cause subjects to think about their verbal descriptions during recognition but more generally to shift the way the test faces are processed, then instructions to ignore the specific contents of their verbalizations may fail to address the source of subjects' difficulty, thereby failing to prevent the verbal interference. In fact, orienting subjects to assess their memories of the face in terms of its possible sources (i.e., their having seen or described the face) may have encouraged them to use a featural strategy during the test and, consequently, worsened recognition performance. From a source-monitoring point of view, careful examination of memories should lead to better source accuracy, but only if individuals are assessing the "right" qualities for the test.

\section{EXPERIMENT 2}

In Experiment 2, two mechanisms for a verbal overshadowing effect were examined: (1) source confusion between competing memory representations may diminish recognition of the target face, and (2) recognition performance may be impaired by a holistic-to-featural shift in the way the test faces are processed. If source confusion between two memory representations is a factor, subjects should show better face recognition performance (i.e., a reduced impairment effect) in conditions that presumably reduce the similarity between the target and potentially competing representations.

Much research has shown that memories containing similar characteristics are more likely to be confused with each other than are memories containing different characteristics (e.g., Dodson \& Johnson, 1996; Ferguson, Hashtroudi, \& Johnson, 1992; Foley, Johnson, \& Raye, 1983; Johnson, Foley, \& Leach, 1988; Lindsay \& Johnson, 1991; Lindsay, Johnson, \& Kwon, 1991). Therefore, to increase the distinctiveness between the original visual memory and the subsequent verbal memory, we included a condition in which subjects were provided with a description of the previously seen face as opposed to their generating a description of the face. Recently, Zaragoza and Lane (1994) found that a similar manipulation affected source-monitoring performance in the eyewitness testimony paradigm. In their study, the subjects were more likely to remember the source of the misleading information (i.e., there were fewer source confusions) on a source test when they had acquired this information by reading a description as opposed to generating answers to questions. Zaragoza and Lane reasoned that the representation of the misleading information was more similar to the representation of the original visual event when subjects generated answers to questions than when they read a narrative, consequently causing more source confusion. Therefore, we expected that, in our study, when subjects read another's description of the target face, they should either experience less confusion, even in the absence of the ignore instructions, or be better able to ignore the competing representation once they had been made aware of its potential for confusion.

A verbal overshadowing effect might also be a consequence of a shift toward more featural and less global processing induced by thinking about facial features. On 
this view, reading someone else's description of the target face should produce a verbal overshadowing effect similar to that found in the standard verbalization (i.e., generate a description) condition. According to the processingshift explanation, it is unclear how the instructions to ignore the generated or read description should affect performance.

Finally, a way to evaluate the relative contributions of these two mechanisms comes from the results of a condition in which subjects were instructed to describe a completely different face (say, their parent's) after viewing the target face. If the confusion is largely representation centered, this describe-parent condition should not affect performance, because a parent's face is presumably very dissimilar from the target's face and therefore should produce little, if any, interference. However, if the verbal overshadowing effect is primarily caused by a processing shift, then the describe-parent condition should impair recognition of the target face, because the act of describing a parent's face, as in describing any face, tends to focus on features. The similarity of the face to the target face should not matter according to this explanation.

In sum, in addition to the standard control condition, some subjects either generated (i.e., the verbalize condition) or were provided with (i.e., the provide condition) a description of the previously seen face. The descriptions that were provided to subjects were actual descriptions of the target face that had been generated by other subjects. Some subjects in both of these conditions, the generated and the provided, received the "ignore" instructions that were used in Experiment 1. We also directed some subjects to describe their parent's face after viewing the target face. Finally, instead of using the video from Experiment 1, we showed subjects a photograph of the target face.

\section{Method}

Subjects. There were 240 male and female Princeton students or visiting students in this study, with 40 subjects in each condition. Each subject was either paid or given course credit.

Materials. There were two different target faces with corresponding recognition-test line-up slides. The photographs of the target faces had similar dimensions and were taken from the candid and formal sections of college yearbooks. The photograph (approximately $4.5 \mathrm{~cm}$ wide and $5.2 \mathrm{~cm}$ high) presented at acquisition was a candid shot of each target face and was mounted on a card that was $15 \mathrm{~cm}$ wide and $10 \mathrm{~cm}$ high. In the recognition test, a formal, professionally posed photograph of the target face was presented alongside five similar looking distractor photographs. Each of the two sets of six test photographs was mounted on a separate card that was $18 \mathrm{~cm}$ wide and $12.5 \mathrm{~cm}$ high. Each of the six test photographs was roughly $4 \mathrm{~cm}$ wide and $5 \mathrm{~cm}$ high. The descriptions provided to some subjects were generated by other matched subjects who were directed to describe the target face.

Procedure. Half of the subjects saw one target face; the remaining subjects saw the other target face. The subjects initially viewed a black-and-white photograph of the appropriate target for $5 \mathrm{sec}$ and then read an unrelated essay for $5 \mathrm{~min}$. The subjects were then randomly assigned to one of six conditions. The subjects in the control condition spent $3 \mathrm{~min}$ attempting to recall and write down the names of the U.S. states and their capitals before taking the final recognition test. The subjects in the verbalize condition were given
3 min to write a description of the previously seen face. They were told to "write a detailed description of the person in the picture so that someone reading the description would be able to identify the person." They then took the recognition test.

After the subjects in the verbal/ignore condition described the face for $3 \mathrm{~min}$, they were given the following instructions:

We're interested in how aware people are of the differences between their memory for seeing a face and their memory for having described this face. When people see the original face again, these differences between their initial memory for the face and their memory for their description sometimes become apparent. In completing the following task, you should ignore your memory for how you described the face and only rely on your memory for seeing the face.

Each subject in the provide and provide/ignore conditions was yoked with a subject in the corresponding verbal or verbal/ignore condition so that the provided descriptions were created by other subjects. The subjects in the two provide conditions were told that "for the next 3 minutes you should read the following description, made by somebody else, of the photo you just saw." After reading the description, the subjects in the provide condition received the recognition test.

Before receiving the recognition test, the subjects in the provide/ ignore condition were given the following "ignore" instructions:

We're interested in how aware people are of the differences between their memory for seeing a face and their memory for having read a description of this face. When people see the original face again, these differences between their initial memory for the face and their memory for their description sometimes become apparent. In completing the following task, you should ignore your memory for how the face was described and only rely on your memory for seeing the face.

The subjects in the describe-parent condition were instructed to spend 3 min writing "a detailed description of the face of one of your parents so that someone reading the description would be able to identify your parent." They then took the recognition test.

The recognition test for all subjects consisted of six similar looking faces, including a different photograph of the target face, and a sheet of paper with six boxes corresponding to the six faces. Each subject was instructed to put a " $\mathrm{V}$ " in the box that represented the face that they initially saw. They were told to choose the person that best resembled or was the person they initially saw. In contrast to the previous experiment, the "not present" option was not available. After making their choices, all subjects were asked to rate their confidence in their choices on a scale from 1 (guessing) to 9 (certain).

\section{Results and Discussion}

Table 2 presents the mean proportion correct recognition and the combined recognition and confidence scores for all groups. This combination score, which has a range of 1 to 6, was determined in the same way as in Experiment 1 . There are 40 combination scores for each group,

Table 2

Recognition and Recognition Weighted by Confidence Scores for Experiment 2

\begin{tabular}{lccc}
\hline & $\begin{array}{c}\text { Percentage } \\
\text { Correct } \\
\text { Recognition }\end{array}$ & $\begin{array}{c}\text { Recognition } \\
\times \text { Confidence } \\
\text { Scores }\end{array}$ & $S E$ \\
\hline Control & 65 & 4.38 & .35 \\
Describe parent & 53 & 3.63 & .34 \\
Verbal & 53 & 3.72 & .33 \\
$\quad$ Self-paced & 38 & 3.23 & .30 \\
$\quad$ Ignore & & & \\
Provide & 45 & 3.48 & .31 \\
$\quad$ Self-paced & 63 & 4.15 & .30 \\
$\quad$ Ignore & & & \\
\hline
\end{tabular}


except the verbalize condition, which has 39 scores because 1 subject failed to provide a confidence score. Analyses for the combined score are reported below. Because the pattern was similar for both faces, the following analyses are collapsed across this variable.

As stated earlier, if verbal overshadowing stems from confusion between representations, then performance should improve when the visual memory representation is on average less similar to the verbal memory representation (i.e., by describing a parent's face or by reading another's description of the target face) and when subjects are oriented to notice differences between these two representations (i.e., with the ignore instructions). However, if neither of these manipulations improves performance, it seems safe to assume that confusion between representations does not contribute to the verbal overshadowing effect in this situation. Instead, a shift from processing the faces in a global manner to processing them in a feature by feature manner is a likely explanation.

To examine whether generating a description of any face impairs performance, we compared the control condition with the combined verbalize and describe-parent conditions, and there was a verbal overshadowing effect $\left[F(1,233)=3.18, M S_{\mathrm{e}}=4.13, p<.10\right]$. As is clear from Table 2, performance was no better when subjects described a parent than when they described the target face.

The following analyses examined two questions: (1) Does the verbal overshadowing effect disappear when subjects read someone else's description of the target face? (2) What is the effect of being warned to ignore the memory of the verbal material? An impairment effect does not depend on the act of generating a description of the target face. The subjects in the provide condition were less accurate than the subjects in the control condition $\left[F(1,233)=3.90, M S_{\mathrm{e}}=4.13\right]$. As in Experiment 1, subjects were not helped when they were instructed to ignore their own verbal descriptions of the face: subjects in the verbal/ignore condition were less accurate than subjects in the control condition $[F(1,233)=6.37]$ and slightly worse, but not significantly so, than subjects in the verbalize condition $[F(1,233)=1.17]$.

To investigate our prediction that the ignore instructions are more likely to improve performance when subjects are provided with a description of the target face than when they generate this description, we performed a 2 (ignore/no ignore) $\times 2$ (generate/provide) ANOVA on the verbal self-paced and ignore and the provide self-paced and ignore conditions in Table 2. There were no reliable main effects, but the predicted interaction was marginally significant $\left[F(1,155)=3.53, M S_{\mathrm{e}}=3.85, p<.07\right]$. The ability to recognize the target face was not improved when subjects were asked to ignore descriptions that they had generated (i.e., verbal/ignore condition) relative to subjects in the standard verbal condition. The ignore instructions, however, did improve recognition of the target face when subjects had been provided with descriptions of the target face. Lastly, there was no reliable correlation between the performance of the subjects who generated a description of the target face and the yoked subjects who were provided with these descriptions $[r=.08$; $F(1,78)<1]$. These results are consistent with similar results from Schooler and Engstler-Schooler (1990) and Fallshore and Schooler (1995) and suggest that subjects were not basing a recognition decision on their memory of the specific features that were mentioned in the description.

In summary, there were three important findings in Experiment 2. (1) Subjects were less accurate at recognizing the target face when they had described their parent's face (i.e., describe-parent group) than when they had not described a face (i.e., the control condition). (2) Reading a description of a face can later impair face recognition. And (3) the ignore manipulation was effective at improving recognition accuracy when subjects had been provided with descriptions of the previously seen face but not when subjects had generated their own descriptions of the target face. The fact that subjects were not helped by the ignore instructions when they had generated a description replicates the results from Experiment 1.

Overall, these results provide evidence for two mechanisms that evidently can produce a verbal overshadowing effect. First, the finding that the verbal overshadowing effect disappeared when subjects were directed to ignore their memory of someone else's description suggests that inappropriate representations can be a source of confusion and that source monitoring can be improved with test instructions that tighten subjects' criteria while making memory judgments (e.g., Dodson \& Johnson, 1993; Lindsay \& Johnson, 1989). Second, two other findings suggest that confusion from inappropriate representations is not the only mechanism by which verbal descriptions hurt recognition. If generated descriptions also produced recognition deficits from confusion between different representations, we would expect subjects to profit from ignore instructions (as did subjects who read provided descriptions) and to show more accurate recognition of the target face when the generated descriptions were less similar to the target face. However, performance was not improved when subjects were directed to ignore memories of their own generated descriptions of the target face or when they described a parent's face rather than the target face. These results suggest that generating verbal descriptions disrupts face recognition by shifting the overall strategy subjects use when examining the alternative faces at test. In the General Discussion, we further discuss these two mechanisms and why they might differentially come into play when verbal descriptions are read and generated.

\section{EXPERIMENT 3}

The results of Experiment 2 suggest that the negative effects of verbalization on face recognition can occur even when it is not the target face that is described. This finding is consistent with the idea that, regardless of the specific content of the verbally derived memory, generating a verbal description induces a shift from holistic/ visual processing of the test faces to featural/verbal pro- 
cessing. Although the impairment effect in Experiment 2 of describing a parent's face was comparable to that of describing the target face, the difference between this condition and control performance was only marginally significant. Because of the importance of this comparison for understanding the disruptive effects of verbalization on recognition, a third experiment was conducted that used more subjects and focused exclusively on this critical comparison. In addition, in order to ensure that the task of describing the nontarget face was comparable to the task of describing the target face, we provided subjects with two unfamiliar faces (one male and one female) and subsequently asked them to describe only one of these faces (control subjects described neither face). This paradigm thus enabled us to determine, for each verbalization subject, the effect of verbalizing an unfamiliar face on recognizing both the described face and the nondescribed face. If the specific content of a verbal description mediates the verbal overshadowing effect (e.g., by establishing a representation that can potentially be confused with the target memory), then verbalization should affect recognition only of the face that was described. If, however, verbalization produces a more global shift in processing that is not specifically associated with the particular content of the verbalization, then verbalizing one face should impair recognition of both the described face and the face that was not described.

\section{Method}

Subjects. One-hundred and eighty-seven subjects from the University of Pittsburgh participated in this experiment; they were assigned randomly to conditions. There were three conditions with 62 subjects in the describe-male condition, 62 in the describe-female condition, and 63 in the control condition.

Materials. The photographed male and female faces used in this study were two of the three used in Schooler and Engstler-Schooler's (1990) Experiment 6. The faces presented at study were taken from the candid photo section from a university yearbook. The recognition test included a different photograph of the target face taken from the formal section of the yearbook, alongside five similar looking distractor faces.

Procedure. The subjects viewed, in succession, slides of a male and a female face. Each slide was presented for $5 \mathrm{sec}$ with a 5 -sec interstimulus interval. All subjects were then given a 5-min filler activity of recalling and naming the states in the United States. Then the subjects were assigned to one of three conditions: control group (which continued the filler activity), the describe-male face, and the describe-female face. After $5 \mathrm{~min}$, all subjects were given recognition tests for the male and female faces. The order of the original slide presentations and tests was counterbalanced across subjects.

\section{Results and Discussion}

Confidence measures were not taken with this data set, so performance is based solely on accuracy. The percentage of subjects choosing the correct face in each condition is shown in Table 3 . The effect of verbalization on the verbalized and nonverbalized faces was assessed separately for the male and female faces in order to avoid violating the assumption of independent observations required by a chi-square test. As can be seen in Table 3, compared with the performance of subjects who did not engage in verbalization, verbalization of either the male
Table 3

\begin{tabular}{cccc}
\multicolumn{4}{c}{$\begin{array}{c}\text { Recognition Rates for the Male and Female Faces } \\
\text { in Experiment 3 }\end{array}$} \\
\hline Test & & Describe & Describe \\
Face & Control & Male & Female \\
\hline Male & $57 \%$ & $34 \%$ & $37 \%$ \\
Female & $70 \%$ & $51 \%$ & $48 \%$ \\
\hline
\end{tabular}

or the female face substantially impaired both recognition of the male face $\left[\chi^{2}(2)=8.14, p<.01\right]$ and recognition of the female face $\left[\chi^{2}(2)=7.00, p<.01\right]$. There was no significant difference between the effects of describing the male and female face for recognition of either the male face [i.e., $34 \%$ vs. $37 \% ; \chi^{2}(1)=.13$ ] or the female face [i.e., $51 \%$ vs. $48 \% ; \chi^{2}(1)=.14$ ].

Verbalization impaired recognition of the nondescribed face as much as it did that of the described face. This outcome, along with the negative effect of describing a parent's face in Experiment 2, suggests that describing any face will impair recognition of a target face. These results suggest that describing a face causes some generalized shift in processing at recognition. Subjects in the control group may rely on more global information during the test, whereas the verbalize subjects may rely on more featural information (e.g., the shape of the eyebrows and lips).

\section{GENERAL DISCUSSION}

Consistent with previous research, the results from these studies showed that face recognition suffers when subjects generate a description of a face they have seen (e.g., Schooler \& Engstler-Schooler, 1990). In addition, there were three new findings: (1) The ability to recognize the target face was impaired not only when subjects had described the target face, but also when they had described a very familiar face - their parent's face-or when they had described a previously seen, but novel, face; (2) recognition performance was disrupted when subjects were provided with a description of a previously seen face; and (3) subjects were better able to ignore descriptions that had been provided than those that they had generated. The first set of results suggests that when descriptions are generated, there is little relationship between the content of what has been described (i.e., whether it is the target face, a parent's face, or a novel face) and subsequent recognition performance. These findings argue against a representation-centered explanation of the verbal overshadowing effect that occurs when subjects generate descriptions themselves. If subjects were confusing their representations of the perceived face and the imagined description, we would expect recognition performance to vary as a function of the similarity between the two representations (e.g., Johnson et al., 1988; also see Crowder, 1976, for a general discussion of the relationship between similarity, interference, and forgetting). According to this view, we should have expected improved recognition of the target face when subjects had described a very different face, such as their parent's face or a face of the opposite sex. This was not the case, how- 
ever. Apparently, the magnitude of the recognitionimpairment effect is not affected by the degree of similarity between the target and subsequent faces when subjects generate a description. It remains to be explored how similarity affects recognition performance when subjects hear or read descriptions given by others.

Thus, as Schooler and his colleagues have suggested, verbal overshadowing may sometimes result from a shift in the cognitive strategies that are applied at recognition (e.g., Fallshore \& Schooler, 1995; Schooler, 1989; Schooler et al., 1996). Unfortunately, the present findings do not reveal the precise nature of this apparent processing shift. One likely possibility, however, is that verbalization orients subjects to rely on verbalizable feature information, which is less useful than the nonverbalizable, holistic/configural information that control subjects presumably rely on to make a recognition judgment (see Carey \& Diamond, 1977; Diamond \& Carey, 1986; Wells \& Hryciw, 1984; Wells \& Turtle, 1987). For instance, Fallshore and Schooler (1995) provided evidence that verbalization influences individuals' relative reliance on featural versus holistic/configural information at recognition. They showed that the detrimental effects of verbalization were minimized under conditions designed to hinder the use of configural information (and encourage the use of featural information), such as the recognition of other-race faces (Rhodes, Brake, et al., 1989) and the recognition of inverted faces (e.g., Bartlett \& Searcy, 1993). Apparently, generating descriptions disrupts recognition only under conditions in which holistic processing is an effective default strategy.

Although the verbal overshadowing effect persisted when the similarity between the target face and described face was reduced (i.e., by describing either a parent's face or a different face of the opposite sex), another prediction that follows from the idea that subjects confuse their visually and verbally coded memories fared somewhat better. We expected that conditions designed to make subjects more aware of alternative memory representations would improve performance, as it does in other paradigms in which visual and verbal information are confused (e.g., Christiaansen \& Ochalek, 1983; Dodson \& Johnson, 1993; Lindsay \& Johnson, 1989). Consistent with this expectation, the verbal overshadowing effect disappeared when subjects were told to ignore a description with which they had been provided. The improvement in recognition that is produced by instructions to ignore provided descriptions parallels similar findings from the misleading-suggestion and visual/verbal scenes paradigms (Dodson \& Johnson, 1993; Lindsay \& Johnson, 1989; Zaragoza \& Lane, 1994). This suggests that there are similar mechanisms of source confusion in all three paradigms, because source monitoring is improved when subjects are directed to attend to aspects of memory that might differentiate memories from different sources. On the other hand, the verbal overshadowing effect was not reduced when subjects were told to ignore descriptions that they had generated themselves.

We are left with the speculation that two different mechanisms affect face recognition when subjects have de- scribed or read about a face: (1) A processing shift may be the most important mechanism of poor face recognition when subjects have generated a description of a face, and (2) confusion between representations from different sources may be the most important mechanism when subjects read a description of a face. Generating descriptions of faces should invoke an analytic activity insofar as particular features of the face are identified and described. This analytic set presumably carries over to the test and shifts the strategy subjects use to examine the test faces to a featural one. The featural strategy is not affected by the ignore instructions, perhaps because these instructions say nothing about how the test faces should be examined. Instead, the instructions orient subjects to discriminate between potentially confusable representations (i.e., subjects are instructed at test to ignore the verbal representation and to rely on the visual representation). Perhaps recognition performance would improve if subjects were instructed to use a different test strategy, such as a more holistic one.

A different situation occurs when subjects read a description of the face. In this case, subjects may not analyze so much as attempt to construct holistic images or impressions of the described faces. Because comprehending a description promotes a holistic impression of the face, these subjects maintain a holistic test strategy. However, constructed representations that are derived from reading the description may produce confusion with perceptually derived representations from seeing the face and, consequently, cause recognition impairment, as in the provide condition. The ignore instructions, however, can successfully orient subjects to distinguish between these two representations, accounting for the improved performance in the provide/ignore condition. Because there appears to be no reliable relationship between the quality of the description and recognition performance, these constructed images are probably derived from both the information in the description and the subjects' memory for the target face

Our explanation of poor face recognition in terms of both a change in test strategy (i.e., featural processing vs. configural/holistic processing) and source confusion between different representations (i.e., visual vs. verbal) fits in a class of similar characterizations of recognition performance. Dunning and Stern (1994) have suggested that accurate and inaccurate face recognition is associated with different recognition strategies. They found that subjects who agreed with statements indicating a reliance on nonreportable, "automatic" processes (e.g., "his face 'popped out' at me") were more accurate than subjects who agreed with statements associated with strategic processes (e.g., "I compared the photographs to each other in order to narrow the choices"). In this context, it seems possible that verbalization may increase subjects' reliance on reportable strategic processes (e.g., isolating features) at the expense of nonreportable, but more useful, automatic processes (e.g., holistic processing). In addition, recent research by Brandimonte, Schooler, and Gabbino (in press) suggests that verbalization might also 
shift individuals' relative reliance on verbal versus visual memory representations. This possibility is indicated by the finding that verbal overshadowing effects in visualform memory can be attenuated by reinstating the visual context in which the stimuli were encoded. Clearly, additional research is necessary to fully isolate the precise nature of the effect of verbalization. Ultimately, however, it seems likely that various alternative distinctions, such as configural/featural (e.g., Carey \& Diamond, 1977), automatic/strategic (e.g., Dunning \& Stern, 1994), and visual/verbal (e.g., Paivio, 1986), may be useful in helping to characterize the impact of verbalization on recognition performance (see Fallshore \& Schooler, 1995). All of these characterizations emphasize that remembering is a product not only of what is stored and what is activated at test, but also of how that information is evaluated (Johnson et al., 1993).

Finally, our results have some practical implications for understanding the experience of an eyewitness to a crime. Eyewitnesses are often asked to generate a description of whom they saw. Eyewitnesses also often hear descriptions of the perpetrator from other eyewitnesses. The present studies suggest that both the activity of generating and the activity of listening to descriptions of an earlier event can hurt subsequent face-recognition performance because of two different factors: (1) relying on ineffective criteria in examining a line-up of faces, such as using a featural strategy; and (2) relying on an incorrect or less accurate representation of the face for a recognition judgment.

\section{REFERENCES}

BADDELEY, A. D. (1979). Applied cognitive and cognitive applied psychology: The case of face recognition. In L.-G. Nilsson (Ed.), Perspectives on memory research (pp. 367-388). Hillsdale, NJ: Erlbaum.

BARTLETT, J. C., \& SEARCY, J. (1993). Inversion and configuration of faces. Cognitive Psychology, 25, 281-316.

Bower, G. H., \& KaRLIN, M. B. (1974). Depth of processing pictures of faces and recognition memory. Journal of Experimental Psychology, 103, 751-757.

Brandimonte, M. A., Schooler, J. W., \& Gabbino, P. (in press). Attenuating verbal overshadowing through visual retrieval cues. Journal of Experimental Psychology: Learning, Memory, \& Cognition.

BRUCE, V. (1994). Stability from variation: The case of face recognition. Quarterly Journal of Experimental Psychology, 47A, 5-28.

BRUCE, V., \& VALENTINE, T. (1988). When a nod's as good as a wink: The role of dynamic information in facial recognition. In M. M. Gruneberg, P. E. Morris, \& R. N. Sykes (Eds.), Practical aspects of memory: Current research and issues (Vol. 1, pp. 169-174). Chichester, U.K.: Wiley.

CAREY, S., \& Diamond, R. (1977). From piecemeal to configurational representation of faces. Science, 195, 312-314.

Christiannsen, R. E., \& Ochalek, K. (1983). Editing misleading information from memory: Evidence for the coexistence of original and postevent information. Memory \& Cognition, 11, 467-475

Crowder, R. G. (1976). Principles of learning and memory. Hillsdale, $\mathrm{NJ}$ : Erlbaum.

DIAMOND, R., \& CAREY, S. (1986). Why faces are and are not special: An effect of expertise. Journal of Experimental Psychology: General, 115, 107-117.

Dodson, C. S., \& Johnson, M. K. (1993). The rate of false source attributions depends on how questions are asked. American Journal of Psychology, 106, 541-557.

Dodson, C. S., \& JoHnson, M. K. (1996). Some problems with the pro- cess dissociation approach to recognition memory. Journal of Experimental Psychology: General, 125, 181-194.

DUNNING, D., \& STERN, L. B. (1994). Distinguishing accurate from inaccurate eyewitness identifications via inquiries about decision processes. Journal of Personality \& Social Psychology, 67, 818-835.

Durso, F. T., \& Johnson, M. K. (1980). The effects of orienting tasks on recognition, recall, and modality confusion of pictures and words. Journal of Verbal Learning \& Verbal Behavior, 19, 416-429.

Educational Testing Service (1989). Graduate Record Examination. Princeton, NJ: Author.

FALLSHORE, M., \& SCHOOLER, J. W. (1995). The verbal vulnerability of perceptual expertise. Journal of Experimental Psychology: Learning, Memory, \& Cognition, 21, 1608-1623.

Ferguson, S., Hashtroudi, S., \& Johnson, M. K. (1992). Age differences in using source-relevant cues. Psychology \& Aging, 7, 443-452.

Foley, M. A., Johnson, M. K., \& Raye, C. L. (1983). Age-related changes in confusion between memories for thoughts and memories for speech. Child Development, 54, 51-60.

HAShER, L., \& Griffin, M. (1978). Reconstructive and reproductive processes in memory. Journal of Experimental Psychology: Human Learning \& Memory, 4, 318-330.

INTRAUB, H., \& HofFMAN, J. E. (1992). Reading and visual memory: Remembering scenes that were never seen. American Journal of Psychology, 105, 101-114.

JaCOBY, L. L., Kelley, C. M., Brown, J., \& JasechKo, J. (1989). Becoming famous overnight: Limits on the ability to avoid unconscious influences of the past. Journal of Personality \& Social Psychology, 56, 326-338.

Johnson, M. K., Foley, M. A., \& LeACH, K. (1988). The consequences for memory of imagining in another person's voice. Memory \& Cognition, 16, 337-342.

Johnson, M. K., Hashtroudi, S., \& Lindsay, D. S. (1993). Source monitoring. Psychological Bulletin, 114, 3-28.

Johnson, M. K., \& RaYe, C. L. (1981). Reality monitoring. Psychological Review, 88, 67-85.

LiNDSAY, D. S., \& JoHNSON, M. K. (1989). Misleading suggestibility and memory for source. Memory \& Cognition, 17, 349-358.

LiNDSAY, D. S., \& JoHnSON, M. K. (1991). Recognition memory and source monitoring. Bulletin of the Psychonomic Society, 29, 203-205.

LiNDSAY, D. S., JOHNSON, M. K., \& Kwon, P. (1991). Developmental changes in memory source monitoring. Journal of Experimental Child Psychology, 52, 297-318.

Loftus, E. F., Miller, D. G., \& Burns, H. J. (1978). Semantic integration of verbal information into a visual memory. Journal of Experimental Psychology: Human Learning \& Memory, 4, 19-31.

LofTus, G. R. (1978). On interpretation of interactions. Memory \& Cognition, 6, 312-319.

McCloskey, M., \& Zaragoza, M. (1985). Misleading postevent information and memory for events: Arguments and evidence against memory impairment hypotheses. Journal of Experimental Psychology: General, 114, 3-18.

Morris, C. D., Bransford, J. D., \& Franks, J. J. (1977). Levels of processing versus transfer appropriate processing. Journal of Verbal Learning \& Verbal Behavior, 16, 519-533.

Paivio, A. (1986). Mental representations: A dual coding approach. New York: Oxford University Press.

RAYE, C. L., JOHNSON, M. K., \& TAYLOR, T. H. (1980). Is there something special about memory for internally generated information? Memory \& Cognition, 8, 141-148.

ReAD, D. J., \& Schooler, J. W. (1994, July). Verbalization decrements in long-term person identification. Paper presented at the Practical Aspects of Memory Conference, Baltimore County, MD.

Rhodes, G., Brake, S., Taylor, K., \& Tan, S. (1989). Expertise and configural coding in face recognition. British Journal of Psychology, 80, 313-331.

SCHOOLER, J. W. (1989, November). Verbalization can impair the nonverbal components of visual memories. Paper presented at the meeting of the Psychonomic Society, Atlanta.

SCHOOLER, J. W., \& ENGSTLER-SCHOOLER, T. Y. (1990). Verbal overshadowing of visual memories: Some things are better left unsaid. $\mathrm{Cog}$ nitive Psychology, 22, 36-71. 
Schooler, J. W., Ryan, R. S., \& Fallshore, M. (1992, November) Verbalization may induce excessively strategic face processing. Paper presented at the Workshop on Memory Strategies: Theory and Application, Trieste.

SChOOLER, J. W., RYAN, R. S., \& REDER, L. M. (1996). The costs and benefits of verbally rehearsing memory for faces. In D. Herrmann, M. K. Johnson, C. McEvoy, C. Hertzog, \& P. Hertel (Eds.), Basic and applied memory: New findings (pp. 51-65). Hillsdale, NJ: Erlbaum.

STERN, L. B., \& DUNNING, D. (1994). Distinguishing accurate from inaccurate eyewitness identifications: A reality monitoring approach In D. F. Ross, J. D. Read, \& M. P. Toglia (Eds.), Adult eyewitness testimony: Current trends and developments (pp. 273-299). New York: Springer-Verlag.

Tulving, E. (1983). Elements of episodic memory. Oxford: Oxford University Press.

WelLS, G. L., \& HRYCIW, B. (1984). Memory for faces: Encoding and retrieval operations. Memory \& Cognition, 12, 338-344.
Wells, G. L., \& TurTLE, J. W. (1987). What is the best way to encode faces? In M. M. Gruneberg, P. E. Morris, \& R. N. Sykes (Eds.), Practical aspects of memory: Current research \& issues (Vol. 1, pp. $163-$ 168). New York: Wiley.

WINOGRAD, E. (1976). Recognition memory for faces following nine different judgments. Bulletin of the Psychonomic Society, $\mathbf{8}$, 419-421.

Zaragoza, M. S., \& Koshmider, J. W., III (1989). Misled subjects may know more than their performance implies. Journal of Experimental Psychology: Learning, Memory, \& Cognition, 15, 246-255.

Zaragoza, M. S., \& LANE, S. M. (1994). Source misattributions and the suggestibility of eyewitness memory. Journal of Experimental Psychology: Learning, Memory, \& Cognition, 20, 934-945.

(Manuscript received March 27, 1995; revision accepted for publication March 1, 1996.) 